\title{
Prostate cancer incidence and agriculture practices in Georgia, 2000-2010
}

\author{
Michael Welton ${ }^{1}$, Sara W. Robb ${ }^{1}$, Ye Shen ${ }^{1}$, Paul Guillebeau ${ }^{1}$, John Vena ${ }^{2}$
}

${ }^{1}$ University of Georgia, USA, ${ }^{2}$ Medical University of South Carolina, USA

Background: Georgia has prostate cancer incidence rates consistently above the national average. A notable portion of Georgia's economy is rooted in agricultural production, and agricultural practices have been associated with an increased risk of prostate cancer.

Methods: Statistical analyses considered county age-adjusted prostate cancer incidence rates as the outcome of interest and three agricultural variables (farmland as percent of county land, dollars spent per county acre on agriculture chemicals, and dollars spent per county acre on commercial fertilizers) as exposures of interest. Multivariate linear regression models analyzed for each separately. Data were obtained from National Cancer Institute Surveillance, Epidemiology and End Results (SEER) 2000-2010, United States Department of Agriculture (USDA) 1987 Agriculture Survey, and 2010 US Census.

Results: In counties with equal to or greater than Georgia counties' median percent African-American population $(27 \%)$, dollars per acre spent on agriculture chemicals was significantly associated $(P=0.04)$ and dollars spent of commercial fertilizers was moderately associated $(P=0.07)$ with elevated prostate cancer incidence rates. There was no association between percent of county farmland and prostate cancer rates.

Conclusion: This study identified associations between prostate cancer incidence rates, agriculture chemical expenditure, and commercial fertilizer expenditure in Georgia counties with a population comprised of more than $27 \%$ of African Americans.

Keywords: Prostate cancer, Pesticide, Fertilizer, Farming, Occupational health, Environmental health, Disparity, Epidemiology

\section{Background}

The state of Georgia consistently has age-adjusted prostate cancer incidence rates above the national average (approx. 167 versus 162 cases per 100000 male population, 2000-2010). In 2000-2010, African Americans had significantly higher rates of prostate cancer than Whites in Georgia (261.0 versus 144.7 per 100000$)$ and the USA $(245.8$ versus 153.7$) .{ }^{1}$ In addition, Georgia has a prominent African-American population ( $31.5 \%$ versus $13.6 \%$ nationally), an economy rooted in agriculture, and documented racial prostate cancer disparities with geographic clusters in rural areas, making exploration of etiologic factors in this state a priority. ${ }^{2-5}$ Knowledge of potential risk factors for prostate cancer is limited and include African-American race, advancing age, family history, and certain occupations. ${ }^{6}$ Some studies have suggested an increased incidence of prostate cancer among farmers, which may be relevant given Georgia's agricultural-based economy. ${ }^{7-9}$

Though there are contradicting hypotheses, the most common theory attributes an increased risk of

Correspondence to: M. D. Welton, University of Georgia, Athens, GA, USA. Email: michael.welton @gmail.com prostate cancer among farmers to pesticide, fertilizers, and agriculture chemical exposure. ${ }^{7}$ Many commonly used agriculture chemicals disrupt normal endocrine activity and appropriate hormone production. Variability in androgenic hormone production, such as testosterone and dihydrotestosterone, can act to stimulate tumor growth. ${ }^{10}$ In the Agricultural Health study of 55000 men in Iowa and North Carolina, a moderate, but statistically significant association between certain pesticides (methyl bromide and chlorinated pesticides) and prostate cancer incidence in individuals over 50 years of age and individuals with a family history of prostate cancer was detected. ${ }^{11}$ Subsequent investigations of the Agricultural Health Study found pesticide applicators have an elevated risk of prostate cancer, and significant increases in risk of aggressive (distant stage or poorly differentiated) prostate cancer with exposure to organophosphates (Fonofos, malathion, and terbufos) and an organochlorine (aldrin). ${ }^{12-14}$

While there is a large body of literature that supports a positive association between agriculture practices and an increased risk of prostate cancer, a substantial body of evidence posits a protective or null association. Lifestyle factors related to farming such as 
increased physical activity, clean air, reduced smoking, and a healthy diet may lead to a decreased risk of lung, esophagus, bladder, colon, liver, and kidney cancers. ${ }^{7}$ A recent meta-analysis reviewing ten published and two unpublished studies identified a statistically significant protective association between reported pesticide exposure and prostate cancer incidence and null associations between fertilizers and prostate cancer. ${ }^{15}$ Additionally, other investigations from the Agriculture Health Study found no significant relationship between organochlorines and methyl bromide and elevated prostate cancer risk. ${ }^{16,17}$ Furthermore, in recent analyses of the Agricultural Health Study, some of the positive associations between pesticide exposure and prostate cancer incidence were no longer apparent when a longer follow-up with the cohort was evaluated. ${ }^{16,17}$

Despite the large body of research examining the relationship between agricultural practices with prostate cancer incidence, results are inconsistent. Owing to Georgia's relatively high percentage of African Americans and industry rooted in agriculture, investigating the relationship between pesticide and agricultural practices and prostate cancer in Georgia is a priority. This ecological investigation explores the associations between prostate cancer incidence rates in Georgia counties and increased farming activity or agriculture chemical or commercial fertilizer expenditure.

\section{Methods}

Statistical analyses considered county-level ageadjusted prostate cancer rates as the outcome of interest and three agricultural variables (farmland as percent of county land, dollars spent per county acre on agriculture chemicals, and dollars spent on commercial fertilizers) as exposures of interest. County percent African-American population and median county income were considered as potential confounders based on a priori assumptions of an association with prostate cancer incidence. Univariate regression analysis was used to determine unadjusted associations between county age-adjusted prostate cancer rates, exposures of interest, and potential confounders. Multivariate linear regression models were analyzed for each exposure of interest separately, adjusted for potential confounders, and included an interaction term for each agriculture exposure and percent African-American population. Significant interaction $(P<0.10)$ was explored by dichotomizing percent African-American population based on the Georgia counties' median value.

Variables included in the analysis were obtained from National Cancer Institute Surveillance, Epidemiology and End Results Program 2000-2010 (SEER), United States Department of Agriculture (USDA) 1987 Agriculture Survey, and 2010 US
Census. ${ }^{1-3,18}$ Age-adjusted (2000 US Standard Population) incidence rates for Georgia counties $(N=159)$ were obtained from SEER*Stat (Version 8.1.5) for the years 2000-2010. County farm land as percent of total county land, dollars spent on agriculture chemicals, and dollars spent on commercial fertilizers for each county were obtained from the 1987 USDA Agriculture Survey, where estimates were generated from surveys of farms selling at least $\$ 1000$ of agricultural products during the census year. County median income and percent African-American population were obtained from the 2010 Census. A latency period of $13+$ years from agriculture exposure (1987) to prostate cancer diagnosis (2000-2010) was considered appropriate for analysis due to the long latency period of prostate cancer. ${ }^{19}$ The total amount of dollars spent on agriculture chemicals and total amount of dollars spent on commercial fertilizers were divided by the total county land in acres to obtain a relative amount (dollars/acre), comparable between counties. Prostate cancer incidence rate distribution was assessed for normality using Shapiro-Wilk normality test and outlying counties were identified by examining studentized residuals.

Coefficient (beta) values are presented with standard errors (SE), and $P$ values. Associations were considered statistically significant at alpha $\leq 0.05$ and interaction was explored at alpha $\leq 0.10$. All statistical analyses were performed using SAS 9.3 (SAS Institute, Cary, NC, USA).

\section{Results}

One hundred and fifty-six of 159 Georgia counties were included in this study. Calhoun (studentized residual $=4.38$ ), Terrell (studentized residual $=3.36$ ), and Webster (studentized residual $=-2.88$ ) counties were identified as outliers and excluded from further analyses. Data were not available for agriculture chemical expenditure for McIntosh and Newton counties and they were omitted from the analysis, as indicated. Age-adjusted prostate cancer incidence rates were normally distributed (Shapiro-Wilk $=0.993$; $P=0.64$ ), meeting the assumption for linear regression without need for variable transformation.

The mean age-adjusted prostate cancer incidence rate for Georgia counties in 2000-2010 was 150.9 cases per 100000 males. Median farmland as percent of county land was $26.0 \%$ (range $=1.85-71.06 \%$ ), median dollars spent per county acre was $\$ 0.88$ (range $=\$ 0.01-15.14)$, and median dollars spent on commercial fertilizers was $\$ 2.29$ (range $=\$ 0.03$ 17.06). In 2010, the median percent African-American population for Georgia counties was $27.3 \%$ and median county median income was approximately $\$ 37700$. Table 1 displays the characteristics of Georgia counties included in this analysis. 
Table 1 Population characteristics for Georgia counties $(n=156)^{\mathrm{a}}$

\begin{tabular}{lrr}
\hline & Median & Range \\
\hline $\begin{array}{l}\text { Age-adjusted prostate cancer incidence } \\
\quad \text { rate per 100 000 males (2000-2010) }\end{array}$ & 150.9 & $68.5-228.1$ \\
$\begin{array}{l}\text { Farmland as percent of total county } \\
\quad \text { land (1987) }\end{array}$ & 26.0 & $1.9-71.1$ \\
$\begin{array}{l}\text { Dollars/acre spent on agriculture } \\
\quad \text { chemicals (1987) }\end{array}$ & 0.9 & $0.01-15.1$ \\
$\begin{array}{l}\text { Dollars/acre spent on commercial } \\
\quad \text { fertilizers (1987) }\end{array}$ & 2.3 & $0.02-17.1$ \\
$\begin{array}{l}\text { Percent African American (2010) } \\
\text { County Median Annual Income } \\
(\$ 1000)(2010)^{d}\end{array}$ & 27.3 & $0.4-74.1$ \\
\hline
\end{tabular}

Note: ${ }^{a}$ Calhoun, Terrell, and Webster were identified as outliers and deleted from analysis.

${ }^{\mathrm{b}}$ Mean (SD) $=152.4$ (29.9)

${ }^{c} n=154$, data not available for Mclntosh and Newton counties

${ }^{\mathrm{d}}$ Reported as thousands of dollars.

Univariate analysis revealed a significant positive association between percent African-American population and county age-adjusted prostate cancer incidence rates $(P<0.0001$; Table 2$)$. Associations between percent county farmland, dollars per acre spent on agriculture chemicals, dollars per acre spent on commercial fertilizers, and median county income were all statistically insignificant. Results from all univariate analyses are presented in Table 2.

Multivariate regression model results for the association between farmland as percent of county land and county prostate cancer age-adjusted incidence rates, adjusting for county median income and percent African American are shown in Table 3. The interaction term between percent African-American population and percent county farmland was significant $(P=0.0247$; Table 3$)$. To explore the interaction between percent African-American population and percent farmland, results were stratified by counties with above/below median percent African-American

Table 2 Univariate regression analysis for Georgia county age-adjusted prostate cancer rates $(2000-2010)$ and selected covariates $(n=156)^{a}$

\begin{tabular}{|c|c|c|c|}
\hline & Beta $^{b}$ & SE (beta) ${ }^{c}$ & $P$ value \\
\hline $\begin{array}{l}\text { Farmland as percent of } \\
\text { county area }\end{array}$ & -0.03 & 0.14 & 0.8588 \\
\hline $\begin{array}{l}\text { Dollars spent per county } \\
\text { acre on agriculture chemicals }\end{array}$ & 1.01 & 0.64 & 0.1189 \\
\hline $\begin{array}{l}\text { Dollars spent per county } \\
\text { acre on commercial fertilizers }\end{array}$ & 0.39 & 0.61 & 0.5154 \\
\hline Percent African-American $^{\dagger}$ & 0.57 & 0.13 & $<0.0001$ \\
\hline $\begin{array}{l}\text { County median annual income } \\
(\$ 1000)^{f, g}\end{array}$ & 0.31 & 0.21 & 0.1449 \\
\hline
\end{tabular}

Note: ${ }^{a}$ Calhoun, Terrell, and Webster were identified as outliers and deleted from analysis.

${ }^{\mathrm{b}}$ Beta coefficient.

${ }^{\mathrm{C}}$ Standard error.

d 1987.

${ }^{\mathrm{e}} n=154$, data not available for McIntosh and Newton counties.

f 2010 .

${ }^{\mathrm{g}}$ Reported as thousands of dollars.
Table 3 Linear regression analysis for Georgia county ageadjusted prostate cancer rates (2000-2010) and farmland as percent of total county area $(n=156)^{a}$

\begin{tabular}{|c|c|c|c|}
\hline Variable & Beta $^{b}$ & SE (beta) ${ }^{c}$ & $P$ value \\
\hline tercer & 113.79 & 13.27 & $<0.00$ \\
\hline $\begin{array}{l}\text { Farmland as percent of } \\
\text { county area }^{d}\end{array}$ & & & \\
\hline Percent African-American ${ }^{\mathrm{e}}$ & 0.29 & 0.2 & 0.25 \\
\hline $\begin{array}{l}\text { County median annual income } \\
(\$ 1000)^{\mathrm{e}, \mathrm{f}}\end{array}$ & 0.79 & 1 & P०० \\
\hline Percent farmland $\times$ percent $A A$ & 0.02 & 0.01 & 0.02 \\
\hline
\end{tabular}

Note: ${ }^{a}$ Calhoun, Terrell, and Webster were identified as outliers and deleted from analysis.

${ }^{b}$ Beta coefficient.

${ }^{\mathrm{C}}$ Standard error.

d 1987.

e 2010.

${ }^{\mathrm{f}}$ Reported as thousands of dollars.

population $(27.3 \%)$ (Table 4$)$. In counties with an African-American population greater than or equal to $27.3 \%$, median county income $(P=0.0009$; Table 4) and percent African-American population $(P<0.0001$; Table 4$)$ were significantly associated with higher prostate cancer incidence rates. In counties with less than $27.3 \%$ African-American population, median county income $(P=0.0687)$ was moderately associated with increased prostate cancer incidence rates. Percent county farmland was not significantly associated with prostate cancer incidence in either strata of African-American population.

Multivariate regression analysis including county age-adjusted prostate cancer incidence rates and dollars per acre spent on agriculture chemicals, percent African-American population, county median income, and the interaction between dollars per acre spent on agriculture chemicals and percent African-American population is shown in Table 5. The model revealed an interaction $(P=0.05)$ between African-American population and dollars spent per acre on agriculture chemicals. The multivariate regression model stratified by counties with above or below $27.3 \%$ AfricanAmerican population is presented in Table 6. In counties with $27.3 \%$ or greater percent African-American population, median county income $(P=0.0010$; Table 6), percent African-American population $(P<0.0001$, Table 6), and dollars per acre spent on agriculture chemicals $(P=0.0465$; Table 6$)$ were significantly associated with elevated prostate cancer incidence rates. In counties with below 27.3\% AfricanAmerican population, median county annual income was moderately associated $(P=0.0526$; Table 6$)$ with prostate cancer incidence rates, while adjusting for other variables.

Table 7 displays results from multivariate regression analysis including county age-adjusted prostate cancer incidence rates and dollars per acre spent on commercial fertilizers, percent African-American population, 
Table 4 Linear regression analysis for Georgia county age-adjusted prostate cancer rates (2000-2010) and farmland as percent of total county area, stratified by percent African-American population above or below counties' median, adjusting for percent African-American and median county annual income $(n=156)^{a}$

\begin{tabular}{|c|c|c|c|c|c|c|}
\hline \multirow[b]{2}{*}{ Variable } & \multicolumn{3}{|c|}{$\begin{array}{c}\text { Percent African-American }<27.3 \% \\
(n=77)\end{array}$} & \multicolumn{3}{|c|}{$\begin{array}{c}\text { Percent African-American } \geq 27.3 \% \\
(n=79)\end{array}$} \\
\hline & Beta $^{b}$ & SE (beta) ${ }^{c}$ & $P$ value & Beta $^{b}$ & SE (beta) ${ }^{c}$ & $P$ value \\
\hline Intercept & 122.0 & 15.2 & $<0.0001$ & 52.25 & 22.17 & 0.0271 \\
\hline Farmland as percent of county area $^{d}$ & -0.26 & 0.23 & 0.2753 & 0.23 & 0.17 & 0.1740 \\
\hline Percent African-American ${ }^{e}$ & 0.59 & 0.37 & 0.1114 & 1.30 & 0.28 & $<0.0001$ \\
\hline County median annual income $(\$ 1000)^{e, f}$ & 0.50 & 0.27 & 0.0687 & 1.31 & 0.38 & 0.0009 \\
\hline
\end{tabular}

Note: ${ }^{a}$ Calhoun, Terrell, and Webster were identified as outliers and deleted from analysis.

${ }^{\mathrm{b}}$ Beta coefficient.

${ }^{\circ}$ Standard error.

d 1987.

e 2010.

${ }^{\dagger}$ Reported as thousands of dollars.

Table 5 Linear regression analysis for Georgia county ageadjusted prostate cancer rates (2000-2010) and dollars spent per acre on agriculture chemicals $(1987)(n=154)^{a}$

\begin{tabular}{|c|c|c|c|}
\hline Variable & Beta $^{b}$ & SE (beta) ${ }^{c}$ & $P$ value \\
\hline Intercept & 103.9 & 11.5 & $<0.0001$ \\
\hline $\begin{array}{l}\text { Dollars per acre spent on } \\
\text { agriculture chemicals }^{d}\end{array}$ & -2.5 & 1.8 & 0.1534 \\
\hline Percent African-American ${ }^{\mathrm{e}}$ & 0.57 & 0.16 & 0.0007 \\
\hline $\begin{array}{l}\text { County median annual } \\
\text { income }(\$ 1000)^{\mathrm{e}, \mathrm{f}}\end{array}$ & 0.78 & 0.22 & 0.0004 \\
\hline $\begin{array}{l}\text { Dollars per acre } \\
\text { spent on agriculture } \\
\text { chemicals } \times \text { percent AA }\end{array}$ & 0.78 & 0.22 & 0.0518 \\
\hline
\end{tabular}

Note: ${ }^{a}$ Data not available for McIntosh and Newton Counties; Calhoun, Terrell, and Webster were identified as outliers and deleted from analysis.

${ }^{\mathrm{b}}$ Beta coefficient.

'Standard error.

d 1987.

e 2010.

${ }^{\mathrm{f}}$ Reported as thousands of dollars.

county median income, and the interaction between dollars per acre spent on commercial fertilizers and percent African-American population. The model revealed an interaction $(P=0.0162)$ between AfricanAmerican population and dollars spent per acre on
Table 7 Linear regression analysis for Georgia county ageadjusted prostate cancer rates $(2000-2010)$ and dollars spent per acre on commercial fertilizers $(1987)(n=156)^{a}$

\begin{tabular}{|c|c|c|c|}
\hline Variable & Beta $^{b}$ & SE (beta) ${ }^{c}$ & $P$ value \\
\hline Intercept & 108.0 & 11.8 & $<0.0001$ \\
\hline $\begin{array}{l}\text { Dollars per acre } \\
\text { spent on commercial } \\
\text { fertilizers }\end{array}$ & -3.1 & 1.5 & 0.0398 \\
\hline Percent African-American ${ }^{e}$ & 0.5 & 0.2 & 0.0115 \\
\hline $\begin{array}{l}\text { County median annual } \\
\text { income }(\$ 1000)^{\mathrm{e}, \mathrm{f}}\end{array}$ & 0.8 & 0.2 & 0.0004 \\
\hline $\begin{array}{l}\text { Dollars per acre } \\
\text { spent on commercial } \\
\text { fertilizers } \times \text { percent AA }\end{array}$ & 0.1 & 0.04 & 0.0162 \\
\hline
\end{tabular}

Note: ${ }^{a}$ Calhoun, Terrell, and Webster were identified as outliers and deleted from analysis.

${ }^{\mathrm{b}}$ Beta coefficient.

${ }^{\mathrm{C}}$ Standard error.

d 1987.

e 2010.

${ }^{\mathrm{f}}$ Reported as thousands of dollars.

commercial fertilizers. Table 8 presents the results of the multivariate regression model stratified by counties with above or below 27.3\% African-American population. In counties with $27.3 \%$ or greater percent African-American population, median county income

Table 6 Linear regression analysis for Georgia county age-adjusted prostate cancer rates (2000-2010) and dollars spent per county acre on agriculture chemicals, stratified by percent African-American population, adjusting for median county annual income and percent African-American $(n=154)^{\mathrm{a}}$

\begin{tabular}{|c|c|c|c|c|c|c|}
\hline \multirow[b]{2}{*}{ Variable } & \multicolumn{3}{|c|}{$\begin{array}{l}\text { Percent African-American } \\
\quad<27.3 \%(n=77)\end{array}$} & \multicolumn{3}{|c|}{$\begin{array}{l}\text { Percent African-American } \geq 27.3 \% \\
\qquad(n=77)\end{array}$} \\
\hline & Beta $^{b}$ & SE (beta) ${ }^{\mathrm{C}}$ & $P$ value & Beta $^{\mathrm{b}}$ & SE (beta) ${ }^{c}$ & $P$ value \\
\hline Intercept & 115.2 & 13.8 & $<0.0001$ & 54.2 & 20.8 & 0.0111 \\
\hline Dollars per acre spent on agriculture chemicals ${ }^{d}$ & -0.6 & 1.4 & 0.6758 & 1.4 & 0.70 & 0.0465 \\
\hline Percent African-American ${ }^{e}$ & 0.55 & 0.4 & 0.1605 & 1.2 & 0.28 & $<0.0001$ \\
\hline County median annual income $(\$ 1000)^{e, f}$ & 0.5 & 0.3 & 0.0526 & 1.3 & 0.4 & 0.0010 \\
\hline
\end{tabular}

Note: ${ }^{a}$ Data not available for McIntosh and Newton Counties; Calhoun, Terrell, and Webster were identified as outliers and deleted from analysis.

${ }^{\mathrm{b}}$ Beta coefficient.

'Standard error.

d 1987.

e 2010.

${ }^{\mathrm{f}}$ Reported as thousands of dollars. 
Table 8 Linear regression analysis for Georgia county age-adjusted prostate cancer rates (2000-2010) and dollars spent per acre on commercial fertilizers, stratified by percent African-American population above or below counties' median, adjusting for percent African-American and median county annual income $(n=156)^{a}$

\begin{tabular}{|c|c|c|c|c|c|c|}
\hline \multirow[b]{2}{*}{ Variable } & \multicolumn{3}{|c|}{$\begin{array}{l}\text { Percent African-American } \\
\quad<27.3 \%(n=77)\end{array}$} & \multicolumn{3}{|c|}{$\begin{array}{l}\text { Percent African-American } \geq \mathbf{2 7 . 3} \% \\
\qquad(n=79)\end{array}$} \\
\hline & Beta $^{\mathrm{b}}$ & SE (beta) ${ }^{c}$ & $P$ value & Beta $^{b}$ & SE (beta) ${ }^{c}$ & $P$ value \\
\hline Intercept & 119.0 & 14.2 & $<0.0001$ & 50.9 & 21.1 & 0.0184 \\
\hline Dollars per acre spent on commercial fertilizers ${ }^{d}$ & -1.20 & 1.2 & 0.3153 & 1.2 & 0.7 & 0.0706 \\
\hline Percent African-American & 0.6 & 0.4 & 0.1014 & 1.3 & 0.3 & $<0.0001$ \\
\hline County median annual income $(\$ 1000)^{\mathrm{e}, \mathrm{f}}$ & 0.5 & 0.3 & 0.0839 & 1.3 & 0.4 & 0.0007 \\
\hline
\end{tabular}

Note: ${ }^{a}$ Calhoun, Terrell, and Webster were identified as outliers and deleted from analysis.

${ }^{\mathrm{b}}$ Beta coefficient.

${ }^{\mathrm{C}}$ Standard error.

d 1987.

e 2010.

${ }^{\mathrm{f}}$ Reported as thousands of dollars.

$(P=0.0007$; Table 8), and percent African-American population $(P<0.0001$; Table 8$)$ were significantly associated, and dollars spent on commercial fertilizers was moderately associated $(P=0.706)$ with elevated prostate cancer incidence rates. In counties with below $27.3 \%$ median county annual income was moderately associated ( $P=0.0839$; Table 8$)$ with prostate cancer incidence rates, while adjusting for other variables.

\section{Conclusion}

This ecological analysis aids in directing future research that may assist in identifying populations at increased risk for prostate cancer in Georgia. This study identified statistically significant associations between prostate cancer incidence rates and agriculture chemical expenditure in Georgia counties and moderate associations with commercial fertilizer expenditure, specifically in counties with a higher than median percentage of African Americans. To the best of the authors' knowledge, population race demographics have not been investigated as a factor in the association between agriculture chemical use and prostate cancer rates. No significant associations were found between farmland as percent of county total land and prostate cancer incidence. These results should be interpreted with caution, as this ecologic study design did not analyze individual-level data.

Our results are consistent with previous studies that have found varying associations between involvement in agriculture and prostate cancer risk. We found that associations between agriculture chemical and fertilizer expense and elevated prostate cancer rates were not uniform across all Georgia counties; they were only present in counties with higher percent AfricanAmerican populations. While others studies have investigated differences between African-American and Caucasian men, our results indicate that race demographics may have an impact on all men, regardless of individual race, within the population, which may serve as an indication of disparate regulation enforcement, barriers to health care, or disparities in workplace risk for injury and illness. ${ }^{8,20,21}$

Identification of the exact mechanisms behind these complex racial disparities is poorly understand; however, the geographic distribution of Georgia counties with higher percent African-American populations may suggest underlying etiologic mechanisms. Over $80 \%$ of the 36 counties that compose Georgia's "Upper Coastal Plain" have African-American populations above the state median. ${ }^{3}$ This region is the center of the peanut, cotton, and vegetable production that makes up approximately a quarter ( $\$ 2$ billion) of Georgia's total annual agricultural commodities. ${ }^{4}$ Organophosphate and organochlorine pesticides are commonly used on peanuts and cotton, including specific insecticides identified in the Agriculture Health Study as risks for prostate cancer. Fonofos are commonly used for peanut crops, malathion for cotton, and though it was banned for crops in 1974, aldrin was used for cotton and persists (as dieldrin) in the environment. ${ }^{22-24}$ Increased production of these crops and subsequent increase in related pesticides in these areas may be partially responsible for the observed disparities in our findings.

Agriculture chemical and fertilizer expenditure is not a perfect surrogate for resident's exposure, which limits conclusions regarding their association with prostate cancer incidence. Although we attempted to control for known prostate cancer risk factors in our analysis, by using age-adjusted prostate cancer rates and adjusting for percent African-American population and median county income, the possibility of residual confounding remains. For example, it is possible that county dollars per acre spent on agriculture chemicals and fertilizers is a surrogate for county tax revenues. Increased tax revenue may provide subsidized funding for additional clinics, which provide prostate cancer screening facilities and may increase diagnosis rates. Additionally, while a large portion 
of the counties with higher percent African-American populations were located in agriculturally active regions, others seemed to cluster around urban centers (Atlanta and Savannah), which have higher rates of prostate cancer diagnosis than their rural counterparts. ${ }^{1}$ Lastly, agriculture chemical and fertilizer expense may be related to the age of the county population. Older generations may be more likely to rely on chemicals versus younger generations who may be more likely to use more progressive and organic methods of pest control. This may result in agriculture chemical and fertilizer expense acting as a proxy for age, a principle risk factor for prostate cancer.

It must be recognized that the data used for analysis in this study may not represent the agriculture chemicals currently in use. In general, pesticides and agriculture chemicals change as pests adapt with advancements in chemistry. Many leading agriculture chemicals used today were not yet developed at the time of data collection for this study. Identifying the specific crops produced in Georgia counties with elevated prostate cancer incidence rates may help to isolate agriculture chemicals and pesticides that represent the predominant chemicals of concern. Future investigations should target specific agriculture chemicals that have been identified as risk factors by other studies, such as organophosphates and organochlorines. ${ }^{10,11,14,25}$

Subsequent investigation is essential. Associations revealed in this analysis are subject to flaws and limitations of ecological studies; temporal sequence is not determined, and results cannot be used to identify individual risk factors. Though data were selected to account for the long latency period of prostate cancer, it is impossible to infer a cause and effect relationship. Research methods must be expanded beyond ecological design and analysis, and must employ strategies to collect individual-level data, determine temporal sequence, and cause and effect relationships. Analyses with more sophisticated techniques, such as those with individuallevel data, evaluating spatial autocorrelation and multilevel neighborhood effects, may be warranted. It may be possible to use case-control methods to retrospectively examine individuals with prostate cancer and subsequently determine risk factors related to farming and pesticide exposure. Ideally, a prospective cohort of residents in counties with large African-American populations in agrarian Georgia would be used to address this important research question. The results of this ecologic analysis are not intended to assign individual risk factors for the development of prostate cancer, but rather provide guidance for future exploration.

It is important to recognize the counties eliminated from analysis, though their absence is unlikely to bias results. The counties eliminated from the agricultural expenditure analysis, McIntosh and Newton (population 101505 and 13 839) do not have economies rooted in agriculture. Calhoun, Terrell, and Webster counties were eliminated as outliers. Sensitivity analyses revealed minimal change in the results with their inclusion. When analyses were run including Calhoun and Terrell counties, associations were biased away from null, as they are both counties with high prostate cancer rates (305.4 and 273.5 per 100000 , respectively) and high agriculture chemical expenditure ( $\$ 13.80$ and $\$ 12.18$ per acre, respectively). Inclusion of Webster County, which has a low prostate cancer rate (57.9 per 100000$)$ and an agriculture chemical expenditure above the counties' median (\$4.77), slightly biased the results towards the null. All three counties had percent African-American populations above Georgia county median (61\%, $61 \%$, and $42 \%$ ) and would have been included in the regression model strata that yielded significant results.

The multifactorial etiology of prostate cancer has few certainties and is inundated with complications, confounding, and risk factors that need clarification. The results of this study identify statistically significant associations between prostate cancer incidence rates and percent African-American population and county median income, as well as important associations with agriculture chemical expenditure and commercial fertilizer expenditure in Georgia counties with higher percent African-American populations. Advancements in the understanding of prostate cancer risk in Georgia's agricultural population have potential policy implications. The results of this investigation can be used as a small steppingstone to further investigate agricultural risk factors for prostate cancer with a focus on subpopulations within agriculture settings.

\section{Disclaimer Statements}

Contributors All authors (Welton, Wagner, Guillebeau, and Vena) contributed extensively to the work presented in this paper.

\section{Funding None.}

Conflicts of interest I (we) certify that there is no conflict of interest regarding the material discussed in the manuscript.

Ethics approval Not applicable.

\section{References}

1 National Cancer Institute (NCI). Surveillance Epidemiology and End Results (SEER) Program (SEER*Stat Software 8.1.5). Bethesda, MD: NCI; 2014.

2 United States Department of Commerce, United States Census Bureau. Quick facts: USA. Washington, DC: United States Department of Commerce; 2010.

3 United States Department of Commerce, United States Census Bureau. Quick facts: Georgia. Washington, DC: United States Department of Commerce; 2010. 
4 United States Department of Agriculture (USDA), National Agricultural Statistics Service (NASS), Georgia Field Office. Georgia agricultural facts. Washington, DC: NASS; 2012.

5 Wagner SE, Bauer SE, Bayakly AR, Vena JE. Prostate cancer incidence and tumor severity in Georgia: descriptive epidemiology, racial disparity, and geographic trends. Cancer Causes Control. 2013;24(1):153-66.

6 National Cancer Institute (NCI). Risk factors for prostate cancer development. Bethesda, MD: NCI; 2014.

7 Blair A, Zahm SH, Pearce NE, Heineman EF, Fraumeni JF, Jr. Clues to cancer etiology from studies of farmers. Scand J Work Environ Health. 1992;18(4):209-15.

8 Meyer TE, Coker AL, Sanderson M, Symanski E. A casecontrol study of farming and prostate cancer in AfricanAmerican and Caucasian men. Occup Environ Med. 2007; 64(3): 155-60.

9 Sharma-Wagner S, Chokkalingam AP, Malker HS, Stone BJ, McLaughlin JK, Hsing AW. Occupation and prostate cancer risk in Sweden. J Occup Environ Med. 2000;42(5):517-25.

10 Xu X, Dailey AB, Talbott EO, Ilacqua VA, Kearney G, Asal NR. Associations of serum concentrations of organochlorine pesticides with breast cancer and prostate cancer in U.S. adults. Environ Health Perspect. 2010;118(1):60-6.

11 Alavanja MC, Samanic C, Dosemeci M, Lubin J, Tarone R, Lynch CF, et al. Use of agricultural pesticides and prostate cancer risk in the Agricultural Health Study cohort. Am J Epidemiol. 2003;157(9):800-14.

12 Koutros S, Alavanja MC, Lubin JH, Sandler DP, Hoppin JA, Lynch CF, et al. An update of cancer incidence in the Agricultural Health Study. J Occup Environ Med. 2010;52(11): 1098-105.

13 Cockburn M, Mills P, Zhang X, Zadnick J, Goldberg D, Ritz B. Prostate cancer and ambient pesticide exposure in agriculturally intensive areas in California. Am J Epidemiol. 2011; 173(11):1280-8.

14 Koutros S, Beane Freeman LE, Lubin JH, Heltshe SL, Andreotti G, Barry KH, et al. Risk of total and aggressive prostate cancer and pesticide use in the Agricultural Health Study. Am J Epidemiol. 2013;177(1):59-74.
15 Ragin C, Davis-Reyes B, Tadesse H, Daniels D, Bunker CH, Jackson $\mathrm{M}$, et al. Farming, reported pesticide use, and prostate cancer. Am J Mens Health. 2013;7(2):102-9.

16 Barry KH, Koutros S, Lubin JH, Coble JB, Barone-Adesi F, Beane Freeman LE, et al. Methyl bromide exposure and cancer risk in the Agricultural Health Study. Cancer Causes Control. 2012;23(6):807-18.

17 Purdue MP, Hoppin JA, Blair A, Dosemeci M, Alavanja MC. Occupational exposure to organochlorine insecticides and cancer incidence in the Agricultural Health Study. Int J Cancer. 2007;120(3):642-9.

18 Battaglin WA, Goolsby DA. Spatial data in geographic information system format on agricultural chemical use, land use, and cropping practices in the United States. USGS WaterResources Investigations Report 94-4176. Washington, DC: Census of Agriculture, US Department of Commerce, U.S. Geologic Service; 1987. Available from: http://water.usgs.gov/ pubs/wri944176/.

19 Adami H, Hunter D, Trichopoulos D. Textbook of cancer epidemiology. 2nd ed. New York: Oxford University Press; 2009.

20 Wolff M, Bates T, Beck B, Young S, Ahmed SM, Maurana C. Cancer prevention in underserved African American communities: barriers and effective strategies - a review of the literature. WMJ. 2003;102(5):36-40.

21 Sturm S. Race, gender, and the law in the twenty-first century workplace: some priliminary observations. Univ Penn J Labor Emoly Law. 1998;1(2).

22 United States Environmental Protection Agency (US EPA). R.E.D. Facts: O-ethyl S-phenyl ethylphosphonodithiolate (Fonofos). EPA 738-F-99-019. Washington, DC: US EPA; 1999.

23 United States Environmental Protection Agency (US EPA). Quantitative usage analysis for malathion. Washington, DC: US EPA; 2000

24 US Department of Health and Human Services/Agency for Toxic Substances and Disease Registry (ASTDR). ToxFAQS: Aldrin/Dieldrin. Washington, DC: US Department of Health and Human Services; 1993.

25 Settimi L, Comba P, Bosia S, Ciapini C, Desideri E, Fedi A, et al. Cancer risk among male farmers: a multi-site case-control study. Int J Occup Med Environ Health. 2001;14(4):339-47. 